\title{
In memory of Professor Vadim S. Anishchenko
}

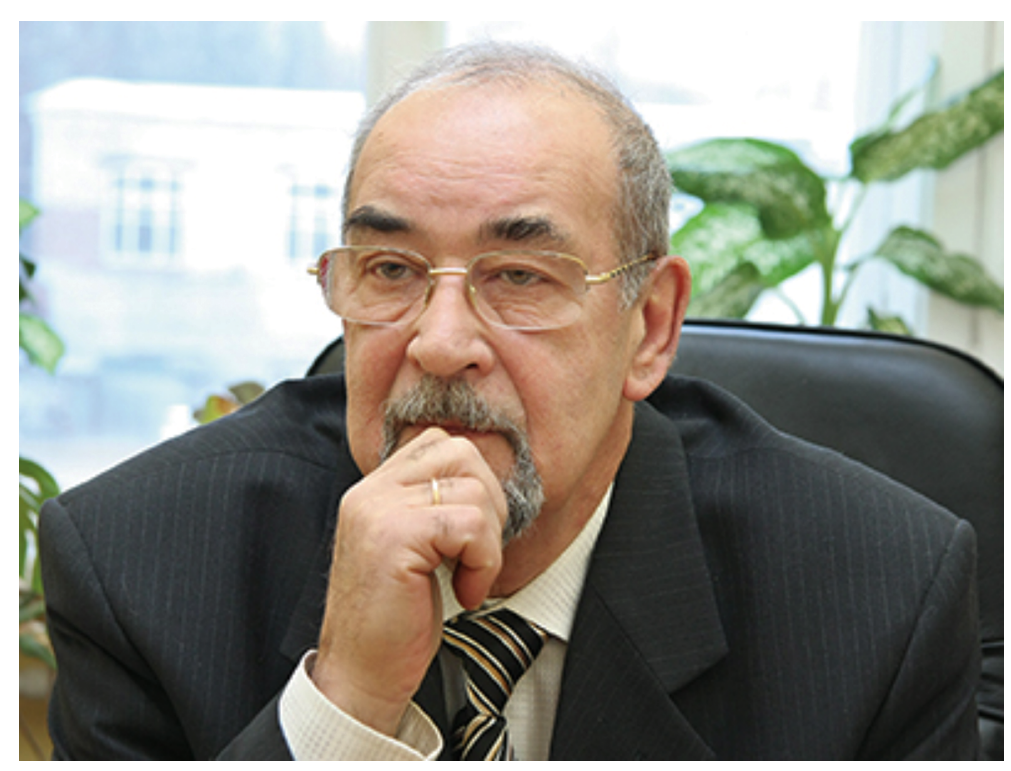

Vadim S. Anishchenko, Professor and Doctor of Physics and Mathematics, the founder of one of the leading scientific schools of radiophysics and nonlinear dynamics, unexpectedly passed away on November 30, 2020, at the age of 77. He was Head of the Department of Radiophysics and Nonlinear Dynamics at Chernyshevsky Saratov National Research State University, an Honored Scientist of the Russian Federation (1995), a recipient of the International Research Award of the Alexander von Humboldt Foundation (Germany, 1999), a Honorary Educator of the Russian Federation (2019), and a Honorary Professor of Saratov State University.

Vadim S. Anishchenko was born on October 21, 1943, in Saratov to the family of a military man. In 1961 he entered Saratov State University, to which he dedicated most of his life. After completing his postgraduate studies in 1970 and earning his $\mathrm{PhD}$, he began a teaching career at the Department of Radiophysics of Saratov State University, where he worked for 50 years. In October 1986, V.S. Anishchenko received a Sc.D. degree. His Sc.D. thesis dealt with a new field of research, namely, dynamical chaos in radiophysical systems. In 1988 he became Head of the Department of Radiophysics of Saratov State University and held this position for the remaining 32 years of his life. He radically reorganized this department, which in 1997 was renamed to the Department of Radiophysics and Nonlinear Dynamics. On the basis of this department, V.S. Anishchenko established a scientific school to study nonlinear phenomena, which later became one of the leading Russian and international scientific schools in this field. He was also one of the main organizers and Director of the Research and Educational Center of Nonlinear Dynamics and Biophysics at Saratov State University. He established the International Institute of Nonlinear Dynamics at the Chernyshevsky Saratov State University. This institute 
has been functioning since 2003. All employees of the Department of Radiophysics and Nonlinear Dynamics and experts from leading European universities are involved in the activities of the institute.

Vadim S. Anishchenko was an internationally recognized expert in nonlinear oscillation theory, the theory of dynamical chaos and synchronization of complex modes and spatial structures in radiophysical and other nonlinear systems, in the theory of fluctuations in nonlinear systems and statistical radiophysics. In 1999 Professor V.S. Anishchenko received an International Research Award for Achievements in Physics from the Alexander von Humboldt Foundation for his work on nonlinear dynamics.

The scientific work of Vadim S. Anishchenko consists of more than 500 publications. Among them are 480 scientific papers, 23 monographs and textbooks, of which 7 were published in the English language. $23 \mathrm{PhD}$ and 7 Sc.D. students received their degrees under his guidance. He also supervised research conducted under more than 40 scientific grants from the Russian Foundation for Basic Research, the U.S. Civilian Research and Development Foundation, the Program of Grants of the President of the Russian Federation, the Ministry of Science and Higher Education of the Russian Federation, the Russian Science Foundation, and the German Physical Society.

V.S. Anishchenko took an active part in the working of many international scientific conferences and schools. He gave over 60 talks and plenary lectures. He also organized 6 international scientific conferences and workshops on nonlinear dynamics in Saratov. V. S. Anishchenko served on the editorial boards of 6 Russian and foreign scientific journals: "Izvestiya Vuzov: Applied Nonlinear Dynamics", "Russian Journal of Nonlinear Dynamics", "Izvestiya: Saratov University. New series. Series Physics", "Discrete Dynamics in Nature and Society", "Discontinuity, Nonlinearity and Complexity", and "Nonlinear Dynamics and Mobile Robotics".

Vadim S. Anishchenko was an excellent pedagogue and lecturer. His lectures on general and special courses, such as the theory of nonlinear oscillations, statistical radiophysics, the theory of stability and bifurcations of dynamical systems, introduction to nonlinear dynamics and introduction to speciality, were notable for bright and memorable treatments and examples, accessibility of explanation even of the most difficult material. V. S. Anishchenko took an active part in the process of introducing and developing a grade-rating system for assessment of teachers' performance at Saratov State University. In October 2013 he was appointed Adviser to the Rector on Science.

V.S. Anishchenko was awarded a Medal of the Order for Merits before Fatherland of the second degree in 2004. In 2008 he was awarded a Medal for Special Merits to Saratov University. In 2012 the title of an Honorary Professor of Saratov State University was conferred on him. In the same year the team led by Prof. V.S. Anishchenko was declared to be a Leading Scientific Educational School of Saratov University.

Many of those who communicated with Vadim S. Anishchenko noted his wide range of interests, fundamental knowledge, the strength of his judgment, and were amazed at his incredible far-sightedness and total commitment to his career. He was a very kind-hearted, responsive, cheerful and caring man. He was loved very much by his friends, colleagues, fellow workers, and students. All who are fortunate to have known him, worked with him and learned from him will remember him all their lives.

Tatyana E. Vadivasova, Galina I. Strelkova, December, 2020 